\title{
Understanding Differential Underachievement in English Among Secondary-School Students from Northern Nigeria
}

\author{
Amina Ahman ${ }^{1}$, Mohammed Kudu Isah ${ }^{2}$, Abubakar Musa ${ }^{3}$ \\ ${ }^{1}$ Department of Languages, Kaduna Polytechnic, Kaduna, Nigeria \\ ${ }^{2}$ Department of Social Sciences, Kaduna Polytechnic, Kaduna, Nigeria \\ ${ }^{3}$ Department of Education Technical, Kaduna Polytechnic, Kaduna, Nigeria
}

Email address:

am_ahman@yahoo.com (A. Ahman), Mohammedkudu65@gmail.com (M. K. Isah), abumusakhalil@gmail.com(A. Musa)

\section{To cite this article:}

Amina Ahman, Mohammed Kudu Isah, Abubakar Musa. Understanding Differential Underachievement in English Among Secondary-School Students from Northern Nigeria. Psychology and Behavioral Sciences. Vol. 9, No. 2, 2020, pp. 6-11. doi: 10.11648/j.pbs.20200902.11

Received: March 18, 2020; Accepted: April 7, 2020; Published: April 23, 2020

\begin{abstract}
Low performance of students in English has been an issue of great concern to education stakeholders in Nigeria. Standardized examination results have consistently shown that students from the northern region perform more poorly than those from the southern part. To this regard, this study combined psychological factors of self-concept, locus of control and students' demographic factors as fundamental in explaining differential English academic achievement of students in northern Nigerian schools. The aim is to identify some of the major factors causing underachievement of students in English. Hence, a quantitative research approach is used for data collection and analysis. The sample comprised 1,227 students drawn from 15 public Senior Secondary Schools in Bauchi, Kaduna and Niger States. Each of the states represents the 3 geopolitical zones of the northern region. A standardized questionnaire was used to measure self-concept and locus of control. The findings indicate a high level of correlation between English self-concept and English achievement, especially in specific domains than the general aspects. The reading self-concept correlated more with the reading achievement. It was therefore suggested among others that teachers should prioritize specific aspect of English to assist underperforming students in particular domains (writing; reading) of English and its corresponding self-concept. Improve in students' performance in English can lead to better performance in other subjects and higher standard of education in the country.
\end{abstract}

Keywords: Underachievement, Academic Attainment, English Self-concept and Locus of Control

\section{Introduction}

The importance of English language in Nigeria cannot be over emphasized, as it is the country's lingual-franca. It serves as a unifying tool for communication among the various linguistic groups in the country. As such, English is the official language that is used to conduct governmental functions, such as making broadcast to the nation, used in the law courts, commerce and industry sectors, science and technology, and as medium of instruction in schools. As a result of the importance accorded to the English language, it is made compulsory for students across the various levels ranging from primary, and secondary school levels, to the tertiary levels of education.

However, despite the commonality of English language use among the people, standardized examination records show the poor performance of students in the subject, especially among those from the northern region. The results from West African Examinations Council (WAEC) and National Examinations Council (NECO) consistently show that the southern students always had higher academic achievement in most subjects. For instance, the 2012 WAEC results indicated that only $1.5 \%$ of students from Yobe State in the north earned the required five or more credits, which is the minimum required score to advance to higher education. The highest achieving state from the north was Kaduna State with $44.4 \%$. In the south, Oyo had $21 \%$ and Abia had $76 \%$, the highest overall rate. Although, the 2018 result showed great improvement in English for NECO in the 2 regions, southern students had $95 \%$ pass, while the northern students still lag behind with 53\%.

The consistent poor performance of northern students in English language has raised serious concerns among 
stakeholders in the region such as parents, teachers, school administrators, policymakers, and the government. [8, 11] This is because English language is the medium of instruction for all the other subjects in the schools. Therefore, low performance in English can have adverse effect on other subjects as well. The consequence is that most students from the north will be unable to gain access to higher education which is crucial for national development. Nonetheless, a credit pass in English is a major requirement to higher education irrespective of students' subject combination. In 2005 , only $19 \%$ of candidates from the northern region had access to tertiary institutions compared with $81 \%$ from the south. [1] This requires urgent attention in order to tackle the low performance in English among the students from the northern region.

Consequently, educational psychologist like [16] in his social learning theory indicated that people's behaviors and activities are contingent on interests, attitudes, perceptions, beliefs, and motivations, which are used to form their own realities. Understanding people's behavioural outcomes, therefore, depends on their interpretation of experiences based on their perceptions, beliefs, interests and attitudes. Likewise, [3] postulates the child as the proximal importance in identifying and improving students' performance before giving consideration to other notable factors such as poor school facilities, infrastructures, pedagogical factors and parental socio-economic.

This study, therefore, considers the exploration of personality factors in relation to the students' performance in English in order to unearth some of the major factors affecting their underachievement in the subject. The aim is to see if the utilization of the personality variables can assist in improving students' English achievement rather than wait for special governmental intervention either to improve school facilities or to increase funding to the schools. However, noting that similar school conditions are obtained in the two regions. This means that the northern students have a similar capability to perform better as those from the south. As a result, this study explored the students' English self-concept and locus of control in relation to the students' English academic achievement in order to understand the major factors contributing to secondary school students' underachievement in English.

\subsection{Statement of the Problem}

Many studies, which have explored self-concepts (SC) and locus of control (LOC) in relation to academic achievement of students, report that people with positive self-concept and internal locus of control are more effective, confident, and have higher academic success than others [15]; [9]. Most of these studies have shown empirically that these concepts are important factors in academic achievement and are mutually interdependent. However, it is worth mentioning that these studies have all been carried out in Western countries such as Australia, the United Kingdom, and the United States. This implies that the case might be different with the Nigerian students due to several factors relating to school facilities, engagement and personality differences.

Nevertheless, considerable research interest in Nigeria has been generated on topics relating to the examination of these concepts (SC \& LOC) along with student performance [13]; [12]; [2]. There is agreement among these researchers that these and other variables facilitate desirable educational outcomes. There is, however, a variation in their focus. For example, [2] examined the influence of self-concept and academic motivation on students' attitudes to mathematics. The findings revealed that students with positive attitude towards maths persevere more, had higher SC, and better score. Likewise, [12] explores the interaction between selfconcept and academic achievement using the English, Maths, and general achievement scores of senior secondary school students in Port Harcourt (southern Nigeria) through the administration of a Self-Descriptive Questionnaire (SDQ III). The most appropriate self-concept instrument for secondary school level is the SDQ II since SDQIII is designed for students at the tertiary levels.

Consequently, this study sets out to examine the relationships between each of these factors (SC \& LOC) with academic achievement among first year secondary school students (SS1) in three states of the north. Each of the state represents the three geo-political zones of the northern region (north-east, north-west and north-central) in order to attain adequate representation. In addition, the study explores other social and demographic factors that have been found in previous studies to provide fundamental insight into students' educational attainments. The aim is to assess the influence of these factors on students from Northern Nigeria in order to generate empirical evidence to inform policy and practice that can be used to raise academic standards in Nigeria. Notably, this is not a comparative study between the performance of the students neither does it aim to make comparisons among the states. The focus is to identify deterring factors on a general aspect of English academic achievement in order to proffer adequate recommendation to assist the students, in raising educational standard in the country.

\subsection{Literature Review}

This section includes explanations of the personality variables of self-concept and locus of control in view of previous studies, theoretical underpinnings and the result of other empirical investigations

\subsection{Conceptual and Theoretical Framework}

The conceptual variables of English self-concept and locus of control are the independent variables or the explanatory variables used to understand differential underachievement of students in English. The students' English language scores represents their academic achievement is the dependent variable. The English self-concept refers to the students' evaluation and perception of their academic performance in English while locus of control refers to the causal attribution of performance outcome. 
Theoretically, self-concept is shown to be multifaceted and hierarchical in nature [19]. [10] observes that specific aspects of academic self-concept correlate more highly with its corresponding academic achievement, and therefore studies in academic self-concept should focus on performance in specific academic area rather than the general areas. This study therefore explores the students' English self-concept with respect to the specific domains of the language skills (reading and writing). These are then correlated with their academic achievement in the corresponding areas. The aim is to establish the students' English self-concept as positive or negative in relation to their performance in the subject.

In theorizing self-concept [4] developed two model that include the skill development model and self-enhancement model. The theories are used to advance either self-concept or academic achievement. The skill development model indicates that academic achievement causally enhances selfconcept, which means that self-concept is a function of academic achievement. This model therefore focuses on the development of students' academic skills in order to improve self-concept. This means that educational practitioners looking to improve students' self-concept should focus on developing interventions targeted towards aspects of academic achievement rather than self-concept itself.

However, [9] criticized the two earlier models as being simplistic for the one-dimensional view of the direction of the relationships between self-concept and academic achievement. They indicated that it was methodologically unsound and inconsistent with self-concept theory, proposing instead the integration of the two theoretical models into a new model called the Reciprocal Effects Model (REM). The REM model shows that prior self-concept affects subsequent achievement and prior achievement affects subsequent selfconcept. This means that self-concept and academic achievement always affect each other, irrespective of which comes first, and this will continue to be so subsequently.

The term locus of control was coined by [17]. He posited that an individual's likelihood of success depends on the extent to which they see themselves as in control over or able to influence events around them. This is the extent to which people perceive themselves to be in control of the activities or events that influence their lives whether they fail or succeed [22]. [18] reported that people are either internal or external in locus of control attributions. Those with internal locus of control internalize the outcomes of their actions when they fail or succeed at something, as they see outcomes of their activities as predicated on their own efforts. They have the tendency to change strategies and persist amidst difficulty until they succeed. On the other hand, people with external locus of control tend to blame their outcomes on factors such as luck, fate, chance, and other people. The fact that they believe that they lack control over events in their lives means that they may not want to try other strategies or persist with the activity and consequently, they may quit trying.

Consequently, people with external locus of control conform more to the law and are easily influenced by others and by events; this is possibly the reason [7] suggest that whether or not people believe a situation or event is under their own control will influence their reward expectancy and behaviour. Similarly, [6] noted that internal locus and external locus individuals differ not only as to their attentiveness to information immediately present in the environment, but also in terms of their actively seeking additional relevant information'. Thus, internals put more effort into improving their skills to succeed in future tasks, while externals do not and are unlikely to perform better, since they attribute the outcome (success or failure) to luck, fate, etc. This study focuses on identifying students control belief as internals or externals in locus of control in relation to their English academic achievement.

\subsection{Research Questions}

1. What is the relationship between English self-concept and English academic achievement among senior secondary school students?

2. What is the relationship between locus of control and English academic achievement among senior secondary school students?

3. Which of the specific aspects of English self-concept correlate more highly with its corresponding academic achievement amongst the students?

4. What are the influences of the sociological factors (gender, ethnicity \&socio-economic status SES) on English academic achievement of the students?

\section{Methods}

The study utilizes survey research design with a qualitative approach to data collection and analysis. The study was conducted among Senior Secondary school students (SS1) in their first year. The samples were drawn from 15 schools across 3 states from each of the geopolitical zones of the northern part of the country, which include Bauchi, Niger and Kaduna states. In selecting the schools, consideration was given based on the type of schools according to gender and locations in the rural and urban centres. Although the students were the unit of sampling and not the schools, their selection reflect the size and type of school in the locality [20]. The reasons for this selection are representation and the pragmatic reasons of convenience, cost, and safety, especially with high rate of insurgency and kidnapping activities. This is the reason for not listing the names of the schools in the study.

Overall, five schools each were girls only, boys only and mixed. Ten of the schools were located in the urban centres and five in the rural areas. The sample is comprised of 1,227 SS1 students who participated in the survey, which amounts to $25 \%$ of the student population of SS1 students from the selected schools. A systematic sampling technique was used to select the sample from the schools. A proportionate sample of respondents was obtained based on the population of the students at the schools. Specifically, every fourth student was selected to participate from a list of SS1 students in the 
schools.

For the instruments, standardized questionnaires for measuring self-concept and locus of control were adapted, with a little tweak to make it appropriate for the respondents. The items for self-concept were from [10] Self-Description Questionnaire II (SDQII) while locus of control was drawn from internal and external scale. The items responses were designed on a five point likert scale of strongly agreed (SA), agreed (A), undecided (U), disagreed and strongly disagreed (SD). The items were further validated by experts in the field. This process yielded Cronbach alpha validity and reliability values of 0.78 and 0.81 , respectively. These values are similar to Rotter's validity and reliability values of 0.7 . The English academic achievement comprised of the students; performance in specific domain of the subject. This focused more on the literacy skills of reading and writing skills. These are combined to form their academic achievement used in this study.

The data analyses included correlation and regression analyses. The correlation analysis is used to test the relationships between the self-concept and locus of control on academic achievement while the regression was used to determine the collective and individual contribution of each of the variables on the students' academic achievement, including the demographic factors.

\section{Presentation of Findings}

In order to answer the research questions, each of the concepts (self-concept, locus of control and academic achievement) were measured separately before the relationships between them were explored

Self-concept and Locus of Control in Relation to English Academic Achievement

Table 1. Correlation between Self-Concept and Locus of Control with Academic Achievement.

\begin{tabular}{llll}
\hline Variables & English Academic Achievement & Locus of control & Sig \\
\hline English Self-concept & 0.811 & & .000 \\
Locus of control & & 0.380 & .000 \\
\hline
\end{tabular}

$\mathrm{N}=1227$

Source: Authors' field survey (2019)

This result indicates $81 \%$ level of relationship between self-concept and English academic achievement. This means that most of the students with high English self-concept also have high scores in the subject, while those with low English self-concept had low English achievement. The result for locus of control indicates low levels of relationships. The indication is that the English self-concept has more impact on the students' performance in English than the LOC. Those with internal LOC were expected to be high achievers while those with external locus were expected to have low scores in English achievement, rather than having students of different achievement level as internals in terms of performance.

The multiple regression analyses indicate a high variance of $\left(R^{2}\right) 75 \%$ in English academic achievement. The variables used to construct the model include the conceptual variable of SC, LOC, and the students' demographic factors such gender, parents' socio-economic status and the type of schools attended in terms of gender and location.

Table 2. Results indication aspects of English academic achievement and corresponding self-concept.

\begin{tabular}{lllll}
\hline Variables & Reading Achievement & Writing Achievement & English achievement & Sig \\
\hline Reading Self-concept & 0.972 & & 0.723 & .000 \\
Writing self-concept & & 0.682 & 0.576 & .000 \\
English self-concept & & & 0.640 & .000 \\
\hline
\end{tabular}

Source: Authors' field survey (2019)

This result in table 2 indicate a high relationship (0.97) between reading self-concept and its corresponding achievement compared with that of writing (0.7) and the general English self-concept and academic achievement. The specific aspects of the English self-concept relates more highly with its corresponding academic achievement that the general aspect.

Table 3. Result of the Multiple Regression Analysis for the Academic Achievement Model.

\begin{tabular}{lllll}
\hline Model & R & R Square & Adjusted-R-square & S E of Estimate \\
\hline 9 & 0.870 & 0.754 & 0.752 & 6.392 \\
\hline
\end{tabular}

Source: Authors' field survey (2019)

The result indicates that English self-concept has the highest unstandardized coefficients of $11 \%$, followed by mother's level of education their school location and the locus of control. This implies that a unit increase in the selfconcept score corresponds to an increase of 11 marks in the students' English achievement; while having a mother who works in the formal sector increased the student's achievement score by about 5 marks.

\section{Discussion of Findings}

The result of the correlation between English self-concept 
and English academic achievement indicate high levels of relationship. This means that students with high English selfconcept have high academic achievement, while those with low self-concept also have low academic achievement. The result conforms to most of the findings of previous studies on the concepts [5], [12]; [9]. The second aspect indicates high level of correlation between the specific aspects of selfconcept and their corresponding academic achievement in reading and writing than the combined academic achievement.

Similarly, [5] study found specific domains (speaking skill) with higher levels of correlation than the general English self-concept. This study used the reading skill as its specific aspect in relation to the scores for the reading ability. However, the study by [15] found a negative correlation. This latter study was among university students which may mean that their perception level of English language and performance is not fully developed for such independent data collection.

For locus of control, the study indicates a low but positive relationship between locus of control and academic achievement (0.68). This finding shows that most of the students, irrespective of their achievement scores, had internal locus of control. This suggests that the most believed that their academic performance in English depends primarily on their own efforts and ability and does not rely on luck or others. [20] study affirmed that the attribution of success or failure to grades and learning is typical among younger groups of students with different achievement levels. Moderate levels of academic expectations and anxiety (which are characteristic of students with external locus of control) among the students who attributed their performance to their own efforts and strategies, justified the weak relationship observed in their study. This is similar to the situation among this study's sample, where $82 \%$ attributed 'doing well in school' to their own efforts, although their performance was low.

The regression model indicated that all the variable used in constructing the model constituted seventy five percent explanatory variable, while for the individual variables show that the English self-concept is the highest contributor in the students' performance followed by the mother's main job ahead of locus of control. The high level of relationship for self-concept means that most of the failure rate is linked to low levels of the students' self-concept. This finding is similar to [9] reciprocal effect model and specificity of selfconcept in specific subject domains. He thereby suggested that both self-concept and academic achievement needs to be enhanced at the same time in order to have lasting and sustained academic achievement over a long period. The second being the mothers educational level which suggests that educated mothers were better positioned to easily identify and assist with school tasks than fathers. They desired and required higher academic performance from their children largely than the less educated mothers [15]. This supports studies that indicate the proximal importance of the mother in children's language development. It was based on these findings that the following conclusions and recommendations were made.

\section{Conclusion and Recommendations}

The study recommends that since English self-concept is a major factor in the students' achievement, intervention activities should target specific aspects of the subject. Also, the EFL teachers should pay particular attention to problem areas and assist students overcome them. The improvement on the specific aspects such as reading and writing can enhance both their self-concept and academic achievement generally. Also, students' progress can easily be noticed when internal frame of reference is used in assessing student's improvement or attainments.

The findings from the regression model indicate the prevalence of mothers' contribution to students' performance in English. It is important for the parents, not just the mother, to have more commitment to their children's performance in English at home. They need to engage more with their assignments and provision of adequate facilities both at home and school. Although the findings indicate less impact of locus of control among the students, they need to make more internal attributions to performance in order to for them to be more persistent and determined in their studies.

Finally, most of these recommendations do require effort, time, and space, but do not entail much fund allocation from policy makers, schools, teachers, and parents. All it takes is adequate engagement on the part of stakeholders to come to the aid of the students in order to help them attain good academic achievement. However, the study notes that the government still has a major role to play in the provision of adequate infrastructure, development of programs to eradicate poverty level of families and improvement of staff welfare. There would be long-lasting effect of the intervention programs and student academic achievement.

\section{References}

[1] Agboola, B. M., \& Ofogbola, F. I. (2010). Access to university education in Nigeria. Benin City, Nigeria: University of Benin. Department of Educational Studies and Management, Faculty of Education. (Unpublished manual).

[2] Ajayi, K. O. and Lawani, A. O. \& Salomi, M. O. (2012) 'The Influences of Self-Concept and Academic Motivation on Students Attitudes to Mathematics in Selected Secondary Schools in Ogun State, Nigeria.'. European Journal of Scientific Research., 67 (3), 444-455.

[3] Bronfenbrenner, U. (2005) 'Making Human Beings Human: Bio-ecological Perspectives on Human Development'. Thousand Oaks, CA: Sage Publications.

[4] Calsyn, R. J. and Kenny, D. A. (1977) 'Self-concept of Ability and Perceived Evaluation of others: Cause or Effect of Academic Achievement', Journal of educational psychology, 6 (9), 136-145. 
[5] Du, M. (2012). A study of the relationship between English self-concept and language learning strategies. Journal of language teaching and research, 3 (3), 508-517.

[6] Darley, W. K. \& Lim, J. S. (1986). 'Family Decision Making in Leisure-Time Activities: an Exploratory Investigation of the Impact of Locus of Control, Child Age Influence Factor and Parental Type on Perceived Child Influence'. Advances in Consumer Research. 13 (1986), 370-374.

[7] Halpert, R. and Hill, R. (2011). 28 Measures of Locus of control. [online]. Dostupné $\mathrm{Z}$ : http://teachinternalcontrol.com/uploads/LOC_Measures_1_.p df. Accessed 23/9/2019, at 3pm.

[8] Maikudi, A. S. (2013) Girl-child Education in Northern Nigeria. Zaria: Ahmadu Bello University Press.

[9] Marsh, H. W. (1990a) 'The Structure of Academic Selfconcept: The Marsh/Shavelson model. Journal of educational psychology, 82 (4), 623-636.

[10] Marsh, H. W. (1990b) 'Causal Ordering of Academic Selfconcept and Academic Achievement: A multi-wave, longitudinal Panel Analysis'. Journal of educational psychology. 82, 646-656.

[11] Ndagi, M. U. (2013). 'A Letter to Northern State Governors 1l'. http://weeklytrust.com.ng/index.php/philosofaith/9092-aletter-to-northern-states-governors-ii. Accessed: 06/02/2018 at $2 \mathrm{pm}$.

[12] Obilor, I. E. (2012). 'Interaction between Self-Concept, and Mathematics, English Language and General Academic Achievement of Senior Secondary Students In Port Harcourt' http://www.hrmars.com/admin/pics/310.pdf.

[13] Oyekuru, B. U., \& Ibegbunam, J. O. (2014). Relationships among test anxiety, locus of control and academic achievement among college students. European Scientific Journal, 10 (13), 387-401.
[14] Onzima E. D. (2011) 'Parents Socio-Economic Status and Pupils Education Attainment in Selected Primary Schools in Malaba Town Council'. Retrieved on 20 Mar 2019 at http://kiu-

ug.academia.edu/RobertOnzima/Papers/551678/Parents_socio economic_status_and_pupils_education_attainment_in_select ed_primary_schools

[15] Pinxten, M., Wouters, S., Preckel, F., Niepel, C., De Fraine, B. \& Verschueren, K. (2015). The formation of academic selfconcept in elementary education: A unifying model for external and internal comparisons. Contemporary Educational Psychology, 41, 124-132.

[16] Rogers, C. (1951) Client-centered therapy: Its current practice, implications and theory. London: Constable

[17] Rotter, J. B. (1954). Social Learning and clinical Psychology. 3rd ed. New York: McGraw-Hill.

[18] Rotter, J. B. (1966) 'Generalized Expectancies for Internal Versus External Control of Reinforcement'. Psychological Monographs: General and Applied, 80 (1), 1-28.

[19] Shavelson, R. J., Hubner, J. J., \& Stanton, G. C. (1976). Selfconcept: Validation of construct interpretations. Review of Educational Research, 46 (1), 407-441.

[20] Shell, D. F. and Husman, J. (2008) 'Beliefs and perceptions about the future: A measurement of future time perspective'. Learning and Individual Differences. 18 (2), 166-175.

[21] Smith, E. M. (2002) Understanding Underachievement: an Investigation into the differential Attainment of Secondary School Pupils. Ph.D. Thesis, Cardiff University.

[22] William, E. (2013). The Effect of Economic Instability on Children's Educational Outcomes. Children and Youth Services Review, 35 (2013), 461-471. 